\title{
Studies on Human Milk III. Secretory IgA Quantity and Antibody Levels against Escherichia coli in Colostrum and Milk from Underprivileged and Privileged Mothers
}

\author{
J.R. CRUZ, B. CARLSSON, B. GARCÍA, M. GEBRE-MEDHIN, Y. HOFVANDER, J.J. URRUTIA AND \\ L. $\AA$ HANSON ${ }^{(34)}$ \\ Department of Clinical Immunology, Institute of Medical Microbiology, University of Gothenburg, Sweden, [B. C., \\ J. J. U., L. A. H.J; Institute of Nutrition of Central America and Panama (INCAP), Guatemala City, Guatemala, \\ [J. R. C., B. G.]; Institute of Nutrition, University of Uppsala, Uppsala, Sweden, [M. G.-M.]; Department of \\ Paediatrics, University Hospital, Uppsala, Sweden [Y. H.]
}

\begin{abstract}
Summary
We studied the milk content of secretory IgA (SIgA) and of specific IgA antibodies to $E$. coli in relation to volume, in $24 \mathrm{~h}$ samples from mothers belonging to different socio-economic groups and living under different ecologic conditions in Ethiopia, Guatemala and Sweden. There were no statistically significant differences in the daily output of milk SIgA among the population groups investigated at different times after onset of lactation. There was, however, a certain trend towards lower SIgA levels among the Guatemalan poor women, compared to the corresponding privileged ones (Tables 2 and 3). Three days after delivery the underprivileged Ethiopian mothers showed significantly lower antibody levels than the privileged Ethiopian. These differences were no longer seen when the values were corrected for differences in volume (Table 5).

One month after delivery, the levels of SIgA antibodies in milk from Swedish women and Guatemalan privileged women against a pool of eight $E$. coli somatic antigens were comparable; these two groups of mothers had significantly higher antibody levels than the Guatemalan rural and urban ones (Table 4). The same pattern was observed after correction for differences in $24 \mathrm{~h}$ volumes (Table 5).

At 3 months after delivery, the Guatemalan urban privileged women, again showed higher levels and daily output of antibodies against the $E$. coli antigens than the urban poor and rural mothers (Tables 4 and 5). The milk samples taken from a population where malnutrition is evident, i.e., mothers from Santa María Cauqué, did not show any changes in the levels of SIgA and the anti-E. coli antibodies 3, 6 and 9 months after initiation of lactation. The data presented here provide evidence that chronically malnourished mothers are able to produce SIgA and transfer it to their offspring via breast milk. Furthermore, they do so in quantities that are comparable to those observed in well-nourished populations. There was a wide range of concentrations and daily output of SIgA and of specific antibodies in all groups, suggesting that some of the infants get less than others. The observed differences in levels of antibodies against $E$. coli may be explained by differences in exposure to $E$. coli strains of the eight serogroups studied here. The possibility of a deficiency in the SIgA antibody response in the undernourished mothers still remains unanswered.
\end{abstract}

\section{Speculation}

After antigenic exposure in the Peyer's patches, committed lymphocytes come from the intestine to the mammary gland, where they produce IgA antibodies. A certain transfer of IgA dimers via the circulation from the intestine to the mammary gland, is also possible. These antibodies are secreted in breast milk and reflect the intestinal exposure of the host to microorganisms and microbial products. It may be feasible to increase the protective potential of breast milk by local intestinal vaccination of pregnant and lactating women, or by parenteral booster following intestinal priming.

Several investigators have addressed the question of composition of breast milk of chronically undernourished populations (for review see 19). The evidence suggests that the concentration of nutrients in milk of undernourished mothers is comparable to that observed in well-nourished women, although there seems to be a trend towards lower protein content, measured as total nitrogen, among the undernourished (30). In addition, the milk volumes produced by underprivileged mothers can be below those reported for well-nourished populations $(4,8,15)$. Although the emphasis so far has been on nutritional aspects, there are reports indicating that the immunologic factors in human milk, including specific antibodies, can be present in largely comparable levels in milk samples obtained from malnourished and well-nourished lactating women $(8,16,25)$.

The difference in antibody prevalence in milk specimens from various countries may reflect different epidemiologic patterns (1, 18 ), but the antibody levels may, in addition, be influenced by the volume of milk produced and/or the ability of the host to respond to an antigenic challenge and to synthesize protein.

Bearing these considerations in mind, we studied the milk content of secretory $\operatorname{IgA}(\mathrm{SIgA})$ and of specific antibodies to Escherichia coli 0 antigens in relation to volume, in $24 \mathrm{~h}$ samples from mothers living under diverse socioeconomic conditions in different countries.

\section{MATERIALS AND METHODS}

Guatemalan mothers. Milk samples, one from each subject, were taken from Guatemalan mothers at different times after parturition. Forty-one of them lived in the capital, Guatemala City, and belonged to two distinct socio-economic groups, designated urban poor and urban privileged; the remaining 45 were from Santa María Cauqué, a rural community where malnutrition is highly prevalent (21). The individuals were recruited as part of a study on nutritional quality of breast milk (29). Mothers to prematures and children born by caesarean section were not included. The mothers and their infants showed no apparent symptoms of disease at the time of sampling.

Determination of milk volumes and collection of the samples. Test-weighing was used to estimate the daily intake of milk by the 
children. Paramedical personnel spent a continuous period of $3 \mathrm{~h}$ at each mother's home. The first 8-h-period was aimed at establishing optimal conditions for normal lactation during the observation phase. The baby was weighed twice before and after every meal. A sample of milk was taken by emptying one breast after the weighing session was completed by manual breast pump manufactured by Lopuco. The milk samples were placed in glass vials, frozen at $-20^{\circ} \mathrm{C}$, transported in dry ice, and not thawed until immediately before analysis, when the samples were defatted and the cells separated by one cycle of centrifugation at $10,000 \mathrm{X}$ $g$ for $10 \mathrm{~min}$. The samples were kept frozen.

Swedish mothers. Sixty-four Swedish women were included in the study. One milk sample was collected from each mother at different times after onset of lactation. The daily milk volume was estimated by weighing the infants as described for the Guatemalan series.

Ethiopian mothers. Twelve Ethiopian mothers were included. They lived in Addis Ababa and belonged to two distinct socioeconomic groups, designated underprivileged and privileged as described in a previous publication (13). Serial colostrum and milk samples were obtained from them at different times after parturition. The daily output of colostrum or milk was estimated by test-weighing.

Immunological techniques. The modified enzyme-linked immunosorbent assay (ELISA) to specifically quantitate SIgA, and described by Sohl-Åkerlund et al. (26) was used. Levels of IgA antibodies against a pool of somatic antigens from eight serotypes of $E$. coli $(01,02,04,06,07,08,018$ and 075) were determined using the same ELISA methodology, as described elsewhere (2). In this study, an anti- $\alpha$ chain antiserum conjugated to alkaline phosphatase was used. It gives a good measure of the SIgA antibodies in milk, since the levels obtained correlate significantly with those found with anti-secretory component conjugate (8). The pool of somatic antigens represents the $E$. coli serogroups commonly found in the gut flora of the Swedish population (31). They are also common in other societies (28). Thus, similar responses have been noted against 0 antigens obtained from $E$. coli isolates from Pakistan and Sweden (8). The antibody levels are expressed as \% of a reference serum, which shows a high level of $\operatorname{IgA}$ anti-E. coli antibodies. The way of expressing the ELISA values was chosen on the basis of statistical evaluation of this special material comparing different modes of determining antibody levels (9). The daily intake of antibody by a child was calculated by correcting this "per cent of reference" for differences in 24-h-volume, in the following manner:

$$
\text { Daily intake }=\% \text { of reference serum }\left(\frac{\text { sample volume }}{968}\right)
$$

The largest volume obtained in the first set of Guatemalan samples studied, $968 \mathrm{ml}$, was taken as the reference volume.

Statistical comparisons. These were made using the Wilcoxon rank sum test and Spearman correlation test (11).

\section{RESULTS}

The population groups. Age, parity and $24 \mathrm{~h}$ milk production is given in Table 1 for all the groups. The mothers in the privileged groups tend to be older and have less children than the poor women.

Comparison of colostrum samples taken 3 and 5 days after delivery. The levels of SIgA/liter in the different colostrum samples are presented in Table 1 . There were no statistically significant differences among the three population groups investigated. A considerable decrease was noted, however, in the SIgA concentration during the first 5 days (Table 2). In spite of the diminution, the daily output of SIgA remained unchanged due to the increase in milk volume (Table $3, P>0.1$ ). The observed differences in daily output of SIgA among the groups were not significant either 3 or 5 days after delivery $(P>0.1)$.

With this information as a baseline, we proceeded to analyze the milk samples for specific antibodies against $E$. coli 0 antigens. Knowing that the daily output of SIgA did not differ significantly among the groups examined, it was possible that, if any differences in levels of specific IgA antibodies were found, they could be due to differences in exposure. The levels of $\operatorname{IgA}$ antibodies against

Table 1. Age, parity and breast milk volume

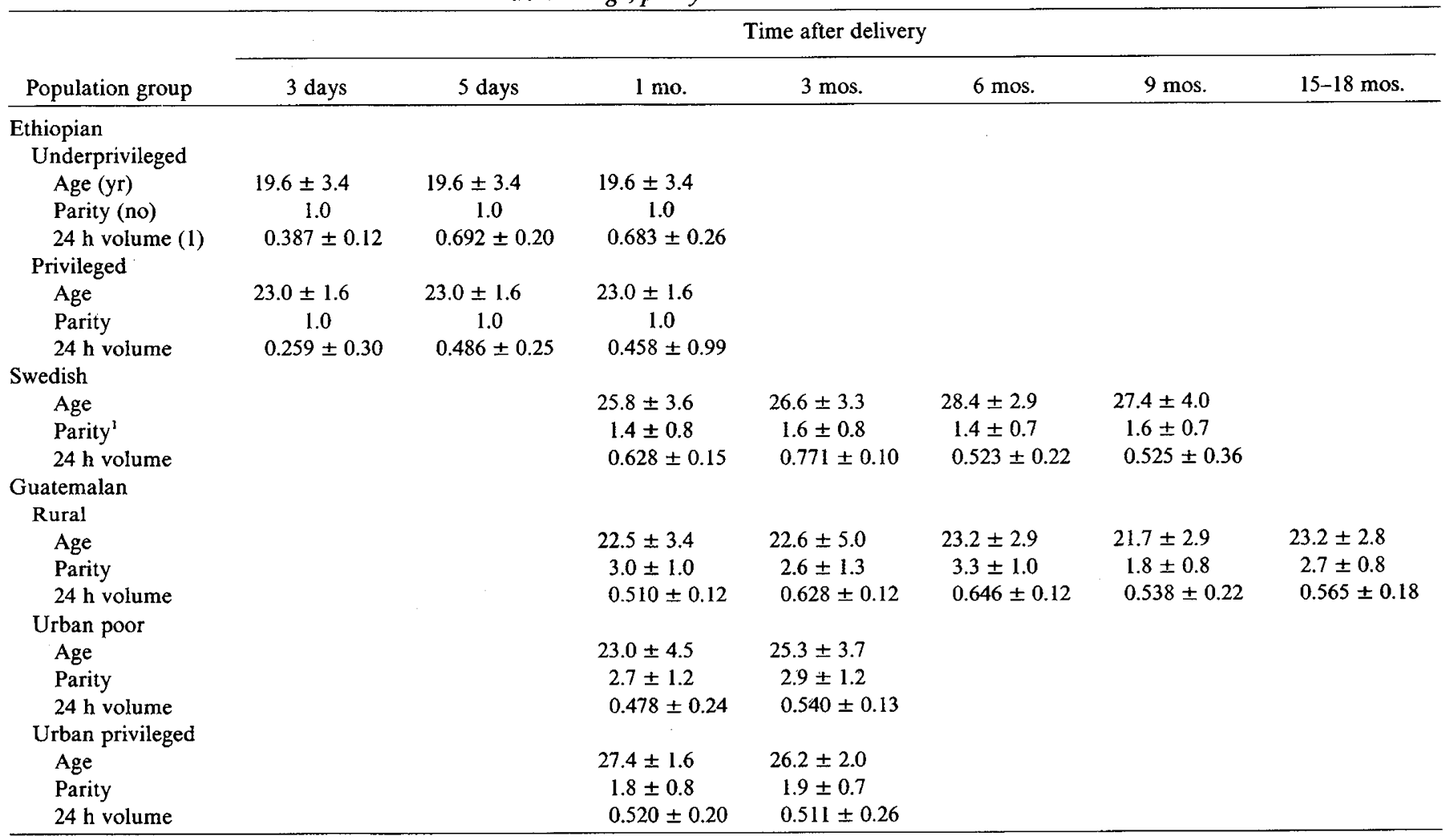

\footnotetext{
'In this group parity $=$ number of live children.
} 
the pool of $E$. coli somatic antigens are presented in Table 4. Three days after delivery the underprivileged Ethiopian mothers showed significantly lower antibody levels than the privileged Ethiopian $(P<0.05)$. All these differences disappeared when the values were corrected for volume (Table $5, P>0.1$ in all cases).

Comparison of samples taken one month after delivery. The levels of SIgA/liter in the different milk specimens are presented in Table 2. Due to the small size of the Ethiopian privileged group, statistical comparisons were possible only among the Swedish and the Guatemalan population groups. The samples obtained from urban privileged women in Guatemala showed higher concentrations than those from the rural mothers $(P<0.1)$. There were no significant differences among the other groups of women. But there was a certain trend toward lower levels in the poor women. The SIgA/liter concentrations showed a wide range within the individual groups, however, with the Guatemalan privileged and Swedish mothers showing the greatest variation. The concentration of SIgA/liter did not vary in dependence of the 24-h-milk volume $(P>0.1)$. When comparing the total amount of $\operatorname{SIgA}$ / liter ingested in $24 \mathrm{~h}$ by the infants being breast fed by these mothers, no significant differences were found $(P>0.1)$. The lowest mean value was observed in the Guatemalan rural group (Table 3).

The levels of IgA antibodies against the pool of eight $E$. coli somatic antigens in milk specimens from Swedish and Guatemalan privileged women were comparable $(P>0.1$, Table 4$)$; these two groups of mothers, Swedish and Guatemalan, had significantly higher antibody levels than the Guatemalan rural and urban ones $(P<0.05$ and $P<0.01)$. The anti- $E$. coli antibodies were present at the same levels in milk specimens from rural and urban poor women $(P>0.1)$. The same pattern was observed after correction for $24 \mathrm{~h}$ volume (Table 5).

There was no correlation between levels of $\operatorname{SIgA}$ and anti-E. coli antibodies $(r=0.17, P>0.1)$.

Comparison of samples taken 3 months and later after delivery. The levels of SIgA/liter in the samples obtained at 3 months after parturition are shown in Table 2. Although there was a considerable range within the individual groups, the rural mothers showed

Table 2. Concentration of secretory $\mathrm{IgA}(\mathrm{g} /$ liter) in milk samples from different countries

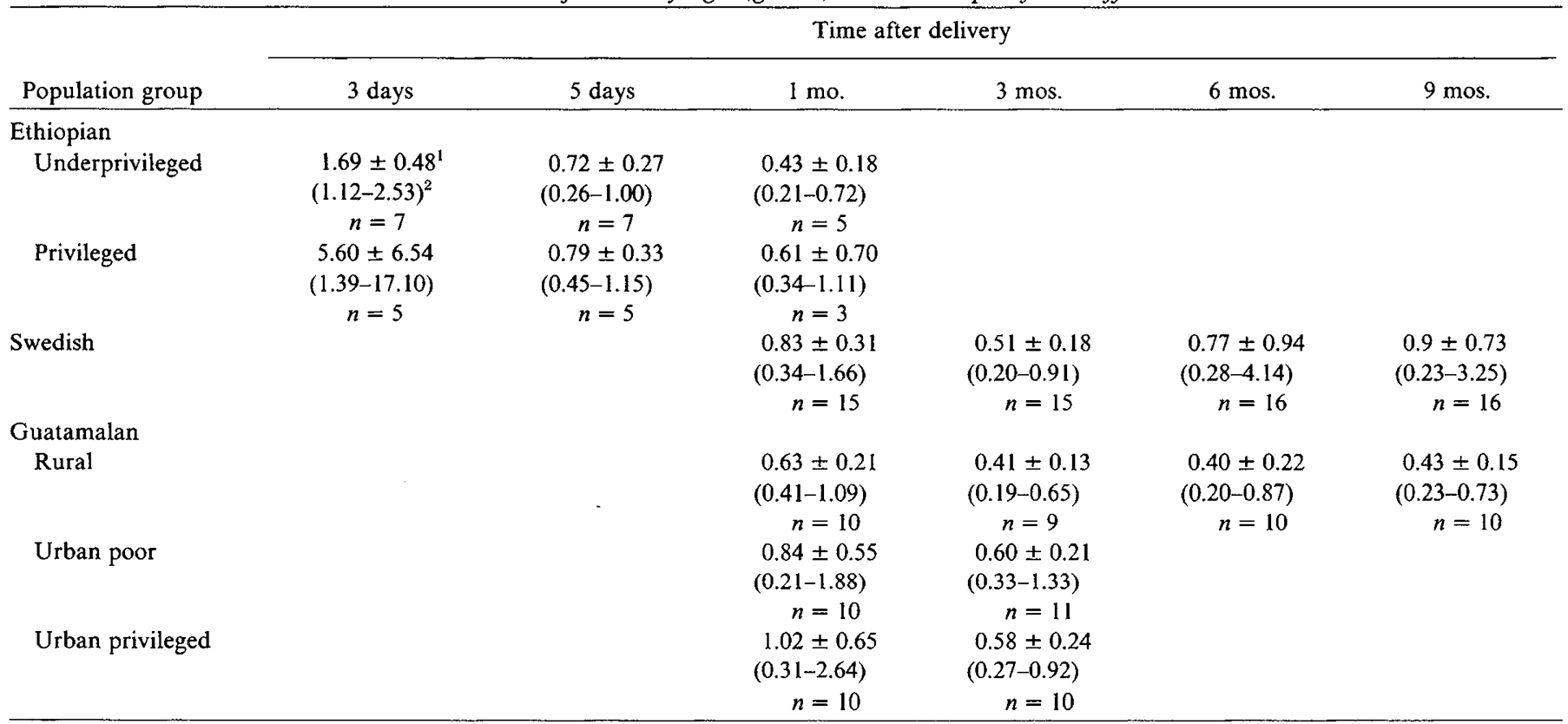

'Arithmetic mean \pm S.D.

${ }^{2}$ Range.

Table 3. Daily output of secretory $\operatorname{IgA}(\mathrm{g})$ by women from different countries

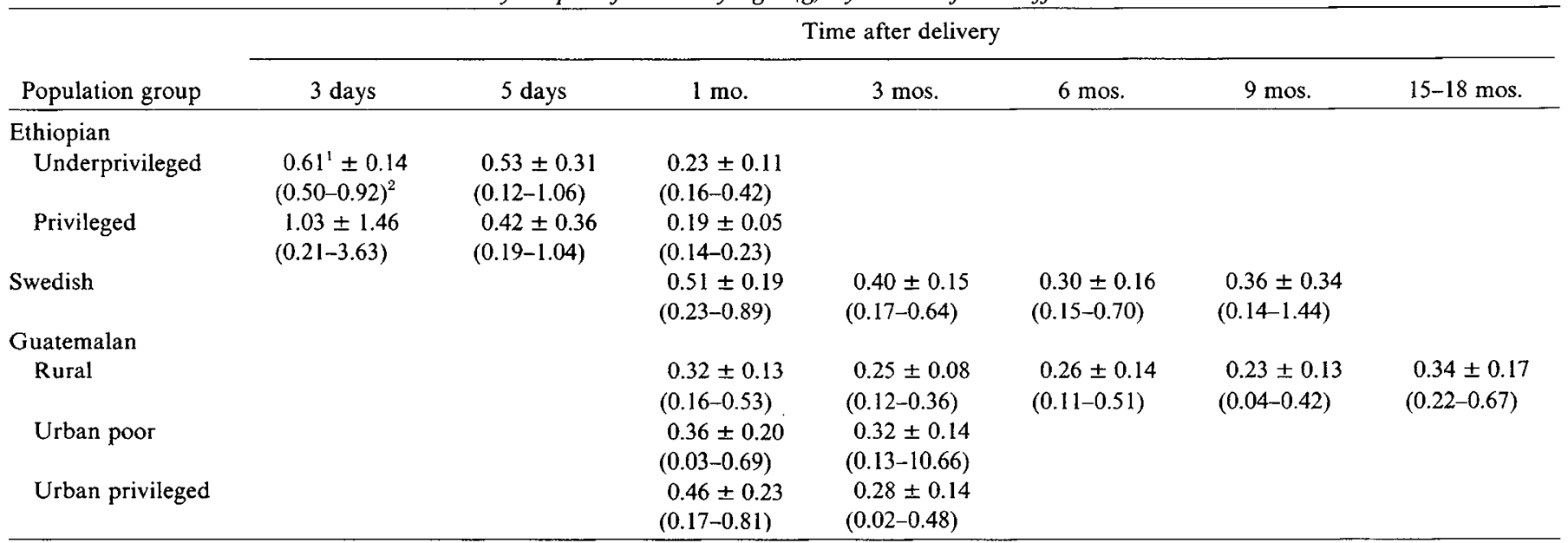

\footnotetext{
' Arithmetic mean \pm S.D.

${ }^{2}$ Range.
} 
Table 4. Anti-E. coli IgA antibodies (\% of reference) in milk samples from different countries

\begin{tabular}{|c|c|c|c|c|c|c|}
\hline Population group & \multicolumn{6}{|c|}{ Time after delivery } \\
\hline \multicolumn{7}{|l|}{ Ethiopian } \\
\hline Privileged & $\begin{array}{l}121 \pm 74.5 \\
(45-246)\end{array}$ & $\begin{array}{l}47 \pm 11.1 \\
(31-58)\end{array}$ & $\begin{array}{l}34 \pm 14.3 \\
(22-58)\end{array}$ & & & \\
\hline \multicolumn{7}{|l|}{ Guatemalan } \\
\hline Rural & & & $\begin{array}{l}14 \pm 7.8 \\
(5-27)\end{array}$ & $\begin{array}{l}13 \pm 13.9 \\
(7-21)\end{array}$ & $\begin{array}{l}22 \pm 19.7 \\
(2-69)\end{array}$ & $\begin{array}{l}12 \pm 6.21 \\
(5-24)\end{array}$ \\
\hline Urban poor & & & $\begin{array}{l}17 \pm 12.5 \\
(7-47)\end{array}$ & $\begin{array}{l}25 \pm 13.9 \\
(7-55)\end{array}$ & & \\
\hline Urban privileged & & & $\begin{array}{l}37 \pm 16.2 \\
(14-68)\end{array}$ & $\begin{array}{c}55 \pm 34.0 \\
(28-121)\end{array}$ & & \\
\hline
\end{tabular}

${ }^{1}$ Arithmetic mean \pm S.D.

${ }^{2}$ Range.

Table 5. Daily output of anti-E. coli IgA antibodies (\% of reference) in milk from different countries

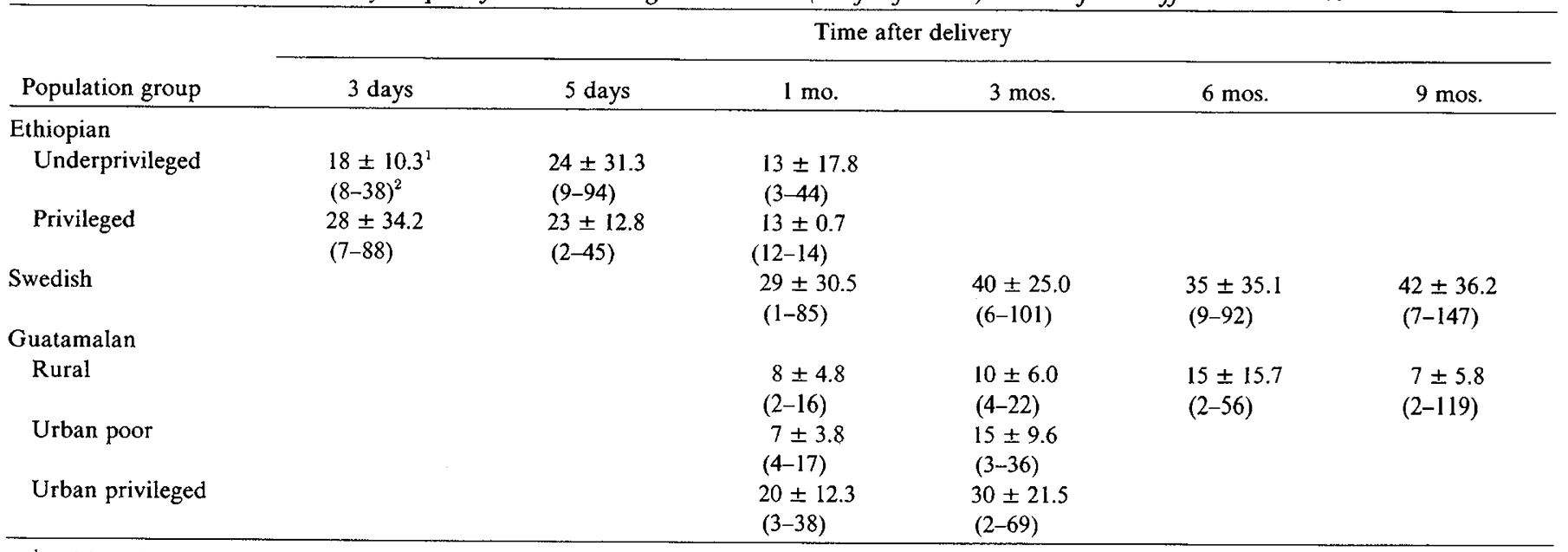

\footnotetext{
${ }^{1}$ Arithmetic mean \pm S.D.

${ }^{2}$ Range.
}

lower levels of SIgA than both the urban poor and urban privileged and Swedish women $(P<0.1)$. Nevertheless, the quantities of SIgA ingested by the children in $24 \mathrm{~h}$ were comparable among the four groups $(P>0.1$, Table 3$)$.

The levels of IgA antibodies against the pool of $E$. coli somatic antigens are presented in Table 4 . The urban privileged and the Swedish women, did not differ in antibody levels again, but both showed higher antibody levels than the urban poor and rural mothers $(P<0.01)$. The privileged mothers had a daily output of IgA anti- $E$. coli antibodies that was significantly higher than the urban poor $(P<0.02)$ and rural women $(P<0.01$, Table 5$)$. The two latter groups did not differ. The mean levels of anti- $E$. coli antibodies in the two urban groups increased in comparison with those observed one month after delivery, in spite of an accompanying decrease in the mean content of SIgA.

The milk samples taken from the chronically malnourished mothers from Santa María Cauqué did not show any changes in the levels of SIgA and of anti- $E$. coli antibodies 3,6 , and 9 months after initiation of lactation (Tables $2,3,4,5$ ). The same was true for the Swedish mothers.

\section{DISCUSSION}

The data presented here provide evidence that chronically undernourished women are able to produce SIgA and transfer it to their offspring via breast milk. Furthermore, they do so in quantities that are comparable to those observed in well-nourished populations.

Although the concentrations of SIgA/liter in general were higher among privileged mothers, the daily output of SIgA by the groups of women from the various socio-economic groups did not differ at the various times after delivery. This fact shows the importance and necessity to determine breast milk volumes whenever studies on the immunological quality of milk are carried out.

The fact that no significant differences in SIgA output were seen among the populations studied suggests that chronically malnourished mothers do not have an impaired SIgA production, as suggested from studies of the nasopharyngeal response of malnourished children and experimental work in rats $(3,10)$. Our findings would rather agree with those of Buchanan et al. (5), who found no differences in the levels of SIgA in urine samples of malnourished and normal children suffering from urinary tract infections. On the other hand, inadequate milk volumes were found in $32 \%$ of poor urban and $25 \%$ of rural women at 6 months of lactation (29), as well as in poor Pakistani women under severe stress (8). In our studies, however, in all instances where a low volume of milk was produced, it was compensated for by higher than average concentrations of SIgA. There were three exceptions, though, one Swedish and two Guatemalan mothers, studied at 1 and 9 months after delivery.

In regard to the variations of the concentration of SIgA in milk 
samples from Guatemalan rural mothers during the period of lactation, a similar pattern was observed among women from Santa María Cauqué (23), mothers living in the U.S. (24) and in Indian mothers (25). The levels of SIgA we present, however, are different. This is presumably due to limitations inherent in the quantitation of SIgA by radial immunodiffusion used in the earlier reports, which have been overcome by the ELISA modification used in this investigation. This modified ELISA measures only $\operatorname{IgA}$ bound to the secretory component and permits the use of a proper standard (26).

The consistent finding of SIgA anti- $E$. coli antibodies presumably formed in the mammary gland might be explained by a transfer of committed lymphocytes from the intestine to the breast $(17,20)$. Such a "homing" to the lactating glands of IgA-producing, primed lymphocytes suggests that milk antibodies reflect the host intestinal exposure to microorganisms and their products. One reason for the observed lower levels of anti- $E$. coli antibodies among the poor women may be variations in prevalence of the eight serogroups studied here. In fact, the Guatemalan privileged women may be exposed by their consumption of heavily contaminated food, such as tortillas, processed outside their home (6).

Additionally, there are reports indicating that, although $E$. coli occurs universally, the predominant serotypes may vary geographically $(12,28,32)$. In a study of the faecal flora carried out in Santa María Cauqué E. coli 055, 0111 and 0119 accounted for two-thirds of the $E$. coli isolates from children less than 2 years old (22). Milk antibodies against $E$. coli 0111 were often found in colostrum samples obtained from mothers living in that locality (23). It seems likely that the antibodies found in human milk are triggered by antigenic challenges to the intestinal mucosa which will not necessarily induce the production of serum antibodies (14). The potential of breast milk as an epidemiological tool becomes apparent.

Our findings indicate that the multiple intestinal disease episodes seen in infants from poor communities may not be due to an impairment of the host immune factors provided by maternal milk. These protective elements, however, may be overcome by the heavy burden of pathogens associated with the low hygienic conditions under which the infants are living. On the other hand, the fact that one-third to one-fourth of the poor women produced too small volumes of milk (29) with a significantly lower daily output of anti- $E$. coli antibodies is important, and suggests that some of the breast-fed babies may be insufficiently protected. It is of interest, therefore, that it may be possible to increase the protective potential of breast milk through local intestinal vaccination and by parenteral boosting of pregnant and/or lactating women $(14,17,27)$.

\section{REFERENCES AND NOTES}

1. Ahlstedt, S., Carlsson, B., Fällström, S. P., Hanson, L. Å., Holmgren, J., LidinJanson, G., Lindblad, B. S., Jodal, U., Kaijser, B., Sohl-Åkerlund, A. and Wadsworth, C.: Antibodies in human serum and milk induced by enterobacteria and food proteins. In: Immunology of the Gut. Ciba Foundation Symposium, 46: 115 (1977).

2. Ahlstedt, S., Carlsson, B., Hanson, L. Å., Kaijser, B., Mattsby Baltzer, I. and Sohl-Âkerlund, A.: Application of the ELISA for determination of immunoglobulin ciass-specified Escherichia coli antibodies. Scand. J. Immunol., 8 (Suppl 7): 119 (1978)

3. Barry, W. S. and Pierce, N. F.: Protein deprivation causes reversible impairment of mucosal immune response to cholera toxoid/toxin in rat gut. Nature, 281: 64 (1979).

4. Baily, K. W.: Quantity and composition of breast-milk in some New Guinean populations. J. Trop. Pediatr., II: 35 (1965).

5. Buchanan, N., Fairburn, J. A., Schmaman, A. and Vos, G. H.: Urinary tract infection and secretory urinary IgA in malnutrition. S. Afr. Med. J., 47: 1179 (1973).

6. Capparelli, E. and Mata, L.: Microflora of maize prepared as tortillas. Appl. Microbiol., 29: 802 (1975).

7. Carlsson, B., Gothefors, L., Ahlstedt, S., Hanson, L. A. and Winberg, J.: Studies of Escherichia coli 0 antigen specific antibodies in human milk, maternal serum and cord blood. Acta Paediatr. Scand, 65: 216 (1976)

8. Carlsson, B.. Ahlstedt, S., Hanson, L. Å.. Lidin-Janson, G.. Lindblad, B. S. and Sultana, R.: Escherichia coli 0 antibody content in milk from healthy Swedish mothers and from a very low-socio-economic group of developing countries. Acta Paediatr. Scand., 65: 417 (1976).

9. Carlsson, B., Ahlstedt, S., Cruz, J. R., Eriksson, B. and Hanson, L. A.: Studies of human milk. II. Analysis of different modes of expressing antibody levels using the enzyme-linked immunosorbent assay (ELISA), In manuscript.

10. Chandra, R. K.: Reduced secretory antibody response to live attenuated measles and poliovirus vaccines in malnourished children. Br. Med. J., 2: 583 (1975).

11. Diem, K. and Lentner, C. (Eds): Scientific tables; 7th Ed., pp. 181, 192, (CibaGeigy, Basle 1971).

12. Eveland, W. C.. Oliver, W. J. and Neel, J. V.: Characteristics of Escherichia coli serotypes in the Yanomama, a primitive indian tribe of South America. Infect Immun., 4: 753 (1971)

13. Gebre-Medhin, M., Wahlquist, A., Hofvander, Y., Uppsäll, L. and Vahlquist, B. Breast milk composition in Ethiopian and Swedish mothers I. Vitamin A and B-caroten G. Am. J. Clin. Nutr., 29: 441 (1976).

14. Goldblum, R. M., Ahlstedt, S., Carlsson, B., Hanson, L. Å., Jodal, U., LidinJanson, G. and Sohl-Åkerlund, A.: Antibody-forming cells in human colostrum after oral immunisation. Nature, 257: 797 (1975).

15. Hanfy, N. M., Morsey, M. R. A., Seddick, Y., Habob, Y. A. and El-Lozy, M.: Maternal nutrition and lactation performance. J. Trop. Pediatr. Environ. Child Health, 18: 187 (1972)

16. Hanson, L. A.., Ahlstedt, S., Carlsson, B., Fällström, S. P., Kaijser, B., Lindblad, B. S., Sohl-Åkerlund, A. and Svanborg Edén, C.: New knowledge in human milk immunology. Acta Paediatr. Scand., 67: 577 (1978).

17. Hanson, L. Å., Carlsson, B., Cruz, J. R., García, B., Holmgren, J., Khan, S. R., Lindblad, B. S., Svennerholm, A-M., Svennerholm, B. and Urrutia, J.: Immune response in the mammary gland. In: Immunology of Breast Milk. Ogra. P. L. and Dayton, D. H., Eds. p. 145 (Raven Press, New York 1979).

18. Holmgren, J., Hanson, L. A.., Carlsson, B., Lindblad, B. S. and Rahimtoola. J.: Neutralizing antibodies against $E$. coli and $V$. cholera enterotoxins in human milk from a developing country. Scand. J. Immunol., 5: 867 (1976).

19. Jelliffe, D. B. and Jelliffe, E. F. P.: The volume and composition of human milk in poorly nourished communities. A review, Am. J. Clin. Nut., 31: 492 (1978).

20. Lamm, M. E., Weisz-Carrington, P., Roux, M. E., McWilliams, M. and PhillipsQuagliata, J. M.: Mode of induction of an IgA response in the breast and other secretory sites by oral antigen. In: Immunology of breast milk. Ogra, P. L., and Dayton, D. H. Eds. p. 105 (Raven Press New York, 1979).

21. Mata, L. J.: The children of Santa María Cauqué: A prospective field study of health and growth. (MIT Press, Cambridge MA 1978).

22. Mata, L. J. and Urrutia, J. J.: Intestinal colonization of breast-fed children in a rural area of low socio-economic level. Ann. NY Acad. Sci. 176: 9 (1971).

23. Mata, L. J. and Wyatt, R. G.: Host resistance to infection. Am. J. Clin. Nut., 24: 976 (1971).

24. Ogra, S. S. and Ogra, P. L.: Immunologic aspects of human colostrum and milk I. Distribution characteristics and concentrations of immunoglobulins at different times after the onset of lactation. J. Pediatr., 92: 546 (1978).

25. Reddy, V., Bhaskaram, C., Raghuramulu N. and Jagadeesann, V.: Antimicrobial factors in human milk. Acta Paediatr. Scand., 66: 229 (1977).

26. Sohl-Åkerlund, A., Hanson, L. Å., Ahlstedt, S. and Carlsson, B.: A sensitive method for specific quantitation of secretory IgA. Scand. J. Immunol., 6: 1275 (1977).

27. Svennerholm, A-M., Holmgren, J., Hanson, L. A., Lindblad, B. S., Quereshi, F., and $\mathrm{J}$. Rahimtoola.: Boosting of secretory IgA antibody responses in man by parenteral cholera vaccination. Scand. J. Immunol., 6: 1345 (1977).

28. Truck, M., Ronald, A., Clark, H., Winterbauer, R., Atlas, E., Silverblatt, F. and Petersdorf, R J.: Studies on the epidemiology of Escherichia coli, 1960-1968. J. Infect. Dis., 170: 13 (1969).

29. Urrutia, J. J. and B. García.: Studies of human milk. I. Daily output by Guatemalan women. In manuscript.

30. Urrutia, J. J., García, B. and Pineda, O.: Estudio sobre cantitad y calidad de leche de mujeres quatemaltecas. Informe anual Instituto de Nutricion de Centro America y Panama p. 77, (INCAP 1979).

31. Winberg, J., Andersen, H. J., Bergström, T., Jacobson, B., Larsson, H. and Lincoln, K.: Epidemiology of symptomatic urinary tract infection in childhood. Acta Paediatr. Scand. (Suppl 252) (1974)

32. Wong, W. T. and Bettelheim, K. A.: Serotypes of Escherichia coli from urinary tract infections in Hong Kong. Zbl. Bakt. Hyg. I. Abt (orig A) 236: 481 (1976)

33. The authors thank Eva Ågren and Eeva Nisshagen who provided invaluable technical assistance.

34. Requests for reprints should be addressed to: Dr. Lars A. Hanson, Department of Clinical Immunology, Institute of Medical Microbiology, Guldhedsgatan 10, 41346 Gothenbourg, Sweden.

35. This research was supported by a WHO training grant to J. R. Cruz, grants from SAREC and the Swedish Medical Research Council (project 215), and the Ellen, Walter and Lenmart Hesselman's Foundation for Scientific Research. This paper was finalized during the tenure of a John E. Fogarty International Center Scholarship in Residence at the National Institutes of Health from August 1979 to September 1980 for Lars Hanson.

36. Received for publication May 19,1980.

37. Accepted for publication July $6,1981$. 